CDD. 800

\title{
Musas interrompidas, vozes silenciadas: a representação da identidade feminina no conto "O retrato oval", de Edgar Allan Poe
}

\section{Interrupted muses, silenced voices: the representation of female identity in Edgar Allan Poe's The oval portrait}

\begin{abstract}
Resumo: O objetivo deste artigo é analisar a representação da identidade feminina no conto "O retrato oval", do autor norte-americano Edgar Allan Poe, dentro da perspectiva dos estudos de gênero, considerando as relações assimétricas de poder entre o personagem masculino e a personagem feminina, bem como a violência simbólica que emerge a partir desta relação. Ao analisar o conto, verificamos que o feminino é representado como um ser silenciado e objeto de uma realização estética masculina, o que confirma a assimetria de poder entre os dois gêneros, além da violência simbólica, que transforma o feminino em um objeto de arte.

Palavras-chave: Gênero. Representação. figura feminina.

Abstract: This article analyzes the representation of the female identity in the short story "The oval portrait" by the North American writer Edgar Allan Poe from the perspective of gender studies, which considers the asymmetrical power relationships between male and female characters, as well as the symbolic violence that emerges from this relationship. The analysis of the short story pointed out that the female image is constructed as a silent being and as the object of a male aesthetical realization, which confirms the asymmetry between the two genders and the symbolic violence that turns the feminine into an object of art.
\end{abstract}

Keywords: Gender. Representation. Female image.

\section{Introdução}

O presente artigo é resultado da pesquisa que deu origem à minha dissertação de mestrado, intitulada "Musas silenciadas, vozes interrompidas: a

"Mestre em estudos de gênero e doutoranda em estudos literários pela Universidade Federal do Paraná (UFPR) E-mail: grebellin@yahoo.com.br 
representação da figura feminina em três contos de Edgar Allan Poe”, defendida no ano de 2010 na Universidade Federal do Paraná. A dissertação constitui-se da análise dos contos "A queda da casa de Usher", "Berenice" e "O retrato oval", do autor norte-americano Edgar Allan Poe (1809-1849), dentro de uma perspectiva que considera o gênero enquanto categoria de análise literária, mostrando que a representação do feminino pode ser interpretada como uma construção social que carrega características da época do Romantismo, tais como a idealização e a busca pela estetização da figura feminina. Durante meu percurso como pesquisadora, pude perceber que os estudos feministas e de gênero oferecem uma possibilidade de interpretação das obras literárias, sem, é claro, esgotá-las. Ao adotarmos uma perspectiva de gênero, estaremos levando em consideração as crenças, valores e atitudes relativos ao gênero que transparecem em uma obra literária. Isso não quer dizer que leremos uma obra preocupando-nos se quem a escreveu foi homem ou mulher, mas sim que podemos lê-la como um construto ficcional capaz de mimetizar as configurações sociais e culturais relativas às experiências de homens e mulheres.

Partindo destas ideias, o objetivo deste artigo é analisar o conto " $\mathrm{O}$ retrato oval", destacando a suposta relação assimétrica entre o personagem masculino, representado como demiurgo, e a personagem feminina, representada como objeto de criação estética. A estetização da figura feminina está presente sobretudo no movimento romântico, no qual percebe-se uma forte tendência a idealizar o feminino, transformando-o em um espetáculo de admiração para o olhar masculino. É também frequente no Romantismo, em especial na obra de Poe, a representação da amada morta, que sinaliza o apagamento do feminino em detrimento de uma realização pessoal e artística masculina. Esta é uma das possibilidades de leitura de "O retrato oval", na qual será levado em consideração o conceito de gênero, que nos permite compreender como os personagens masculino e feminino são construídos no texto ficcional.

Antes de partir para a análise propriamente dita, faz-se necessário definir o conceito de gênero enquanto categoria de análise literária. $\mathrm{O}$ gênero pode ser definido como toda e qualquer construção social, simbólica, culturalmente relativa, da masculinidade e da feminilidade. Ele define-se em oposição ao sexo, que se refere à identidade biológica dos indivíduos. (SCOTT, 1990, p. 5). Desta maneira, gênero não é sexo: ele é uma categoria que se impõe sobre o corpo sexuado, aquilo que faz do ser biológico um sujeito social, seja ele homem, mulher, heterossexual ou homossexual, branco ou negro. Para Teresa de lauretis (apud HOLLANDA, 1992, p. 211), "as concepções culturais de 
masculino e feminino como duas categorias complementares formam, dentro de cada cultura, um sistema de gênero, um sistema simbólico ou um sistema de significações que relaciona o sexo a conteúdos culturais de acordo com valores e hierarquias sociais". Desta forma, os sujeitos não se constituem apenas pela diferença sexual, mas por variadas representações culturais que dizem algo sobre como a sociedade os percebe. Tais representações acabam por formar os sistemas de gênero aos quais a autora se refere, de modo que ser representado (ou se representar) como "homem" ou "mulher" já subentende a totalidade dos atributos sociais associados a homens e mulheres. (LAURETIS, apud HOLLANDA, 1992, p. 212). Em uma sociedade patriarcal, por exemplo, ser representado como homem pressupõe os atributos de força, virilidade e insensibilidade, uma vez que, desde a mais tenra infância, a grande maioria dos homens é advertida de que "homem não chora" e de que qualquer demonstração de sentimentos pode gerar dúvidas em relação à masculinidade. Por outro lado, ser representada como mulher pressupõe a existência de valores tradicionalmente considerados "femininos", tais como a maternidade, a empatia, a sensibilidade e o sentimentalismo, entre outros. Tais características são socialmente construídas, inculcadas através da educação e do aprendizado de atitudes e valores ao longo da vida do indivíduo, o que mostra que não devemos perceber as diferenças entre homens e mulheres como uma mera diferença sexual.

Nos anos 1980 e 1990 torna-se frequente o uso do termo gênero denominando uma categoria de análise literária. Ao considerarmos tal categoria na análise de um texto ficcional estamos pressupondo que o gênero de autoria influencia as representações de mundo contidas neste texto, de forma que não seria possível a produção de uma obra livre de qualquer significado relacionado ao gênero. Rita Felski acredita que a literatura é sobre gênero naturalmente, pois as obras sempre retrataram as vidas de homens e mulheres. A literatura não apenas reforçaria a existência de uma opressão feminina como também seria capaz de trazer ideias, mitos e símbolos relativos ao gênero. Isto nos leva a crer que a obra literária é saturada de significados culturais, ajudando a construir percepções de mundo, além de criar um senso de realidade. (FELSKI, 2003, p.13).

Em obras literárias, o gênero se faz presente através de representações. Neste sentido, é fundamental definir o conceito de representação, objeto de uma série de discussões ao longo de séculos de teoria e crítica literária. Ao representarmos algo, usamos imagens e palavras para descrever o mundo tal 
qual o vemos, re-apresentando-o de acordo com nosso entendimento. Construindo uma representação produzimos sentido por meio da linguagem e das imagens utilizadas, tornando presente, no instante desta representação, uma noção que temos do objeto representado. De acordo com Luís Costa Lima, a articulação entre a arte e a representação se realiza pela noção de figura, algo que "apresenta ou torna visíveis os traços essenciais ou característicos de algo externo, de um espaço ou contexto diverso do estritamente literário" (LIMA, 1981, p. 217). Desta forma, é através de figurações que os elementos externos são trazidos para dentro do texto ficcional, de maneira que a ficção não pode ser entendida como um mero espelho da realidade, e sim como uma transposição do real para o ilusório que se dá por meio de figuras que ilustram este "real". Ainda de acordo com Costa Lima, uma representação é sempre produto de determinadas classificações, pois "cada membro da sociedade se representa a partir dos critérios classificatórios ao seu dispor" (LIMA, 1981, p. 218) Isto faz com que as representações sejam, portanto, "as múltiplas molduras em que nos encaixamos sem nos determos, a maioria das quais aprendemos pelo simples comércio com os outros membros de nosso grupo" (LIMA, 1981, p. 221). Tal noção parece ser verdadeira em relação às representações de gênero, pois quando nos referimos ao masculino ou ao feminino já pressupomos, quase que automaticamente, quais são as características associadas aos dois gêneros, as "molduras" sociais nas quais cada gênero se encaixa, o que remete às classificações referidas por Costa Lima.

A partir destes conceitos, é possível conceber as representações como construtos sociais, uma vez que elas mimetizam modos de ser, valores, concepções e atitudes, fazendo parte de determinados processos culturais que se desenrolam em um dado lugar e em um dado momento histórico. E quando nos referimos à representação da figura feminina na literatura, não podemos nos esquecer que o feminino, sendo também uma construção social, pode ser visto como um reflexo das representações que a cultura faz dele. Estas representações, como produtos culturais, contribuíram e ainda contribuem para o nosso entendimento do que é feminino, revelando as estruturas de poder que permearam e ainda permeiam as relações entre os sexos. Sendo assim, ao retratar uma figura feminina em um texto ficcional um(a) autor(a) não está, necessariamente, falando da mulher real, mas de uma figura cuja ficcionalização não deve ser desvinculada do social, pois tem o poder de carregar as configurações ideológicas de uma época. Entre tais configurações, encontramos, é claro, o gênero. 
As representações de gênero podem se materializar na ficção através de convenções estéticas, que variam conforme a época analisada. Na obra de Poe, são as convenções do Romantismo gótico, vertente na qual surge uma notável tendência a representar as personagens femininas como seres frágeis, doentes e à beira da morte, e os personagens masculinos como artistas excêntricos que dedicam quase todas as suas vidas à realização de um ideal estético. De acordo com Felski, o movimento romântico produziu figuras gendradas, nas quais encontramos ecos de uma sociedade patriarcal que, na maioria das vezes, concebe a criação literária como prerrogativa masculina e reserva ao feminino as imagens de morte, doença e decadência. (FELSKI, 1995, p. 106). E ao morrer, a personagem feminina serve de estímulo para um trabalho artístico, que tem por função preservá-la como uma lembrança que não pode ser esquecida. Daí os inúmeros textos que tratam da morte de uma mulher, textos nos quais o personagem masculino transforma a amada em objeto de arte.

Para Edgar Allan Poe, em seu artigo "A filosofia da composição", a morte da mulher amada é o tema mais poético do mundo, e a pessoa mais apropriada para desenvolvê-lo é um amante despojado de seu amor (POE, 2001, p. 914). Sendo assim, é possível afirmar que se estabelece uma assimetria de poder na qual o feminino ocupa a posição de cadáver e o masculino, a de lamentador da morte da amada. Esta percepção materializa-se nos quadros de alguns pintores românticos, nos quais as figuras femininas são representadas como seres passivos, silenciadas enquanto sujeitos pensantes e atuantes, e alimentando as fantasias masculinas de poder, pois o artista masculino era tanto o proprietário como o espectador da obra. Um bom exemplo disto é o quadro Ophelia (1852), de John Everett Millais (1829-1896), membro do grupo Pré-Rafaelita surgido em $1848^{1}$. O quadro de Millais se tornou paradigmático, pois representa a personagem shakespeariana no momento de sua morte, que se dá através do suicídio por afogamento. E a mulher que morre é sempre jovem e bela, o que aponta para uma glamorização da morte que é paralela a um apagamento da mulher enquanto sujeito autônomo. Desta forma, podemos afirmar que se configura uma violência simbólica de gênero, uma vez que a mulher é "assassinada" em prol de uma realização artística que é, na maior parte das vezes, masculina.

\footnotetext{
${ }^{1}$ A Irmandade Pré-Rafaelita, de acordo com Cristiane Busato Smith (2007), foi um grupo artístico fundado na Inglaterra por Dante Gabriel Rossetti, William Holman Hunt e John Everett Millais. Este grupo, organizado ao modo de uma confraria medieval, almejava realizar uma reforma na arte pictórica britânica mediante a recuperação do estilo dos pintores florentinos da década de 1400, anteriores a Rafael Sanzio. Imbuídos pelo espírito saudosista romântico, estes artistas desejavam devolver à arte a sua pureza e honestidade anteriores, criando um novo tipo de arte, livre das amarras do pensamento acadêmico inglês.
} 


\section{A morte da mulher amada em prol de uma realização estética}

"O retrato oval", pouco conhecido e pouco explorado pela crítica, pode ser interpretado como uma metáfora da criação artística masculina, materializada na figura do artista obcecado pela arte e na representação da personagem feminina como musa inspiradora. $\mathrm{O}$ conto é narrado em primeira pessoa por um narrador não identificado, que diz estar gravemente ferido e resolve passar a noite em um castelo abandonado juntamente com o criado que o acompanha. Após se estabelecer em um cômodo repleto de quadros nas paredes, o narrador resolve mudar a posição do candelabro para melhor poder ler o livro que conta a estória das molduras. Ao fazer isto ele descobre um retrato de formato oval que até então não tinha visto, que traz a figura de uma moça muito jovem e bela, no auge de sua juventude. Curioso, vai procurar no volume o trecho que relata a origem do retrato e descobre que a mulher estava morta há muitos anos, e que tinha morrido ao se tornar a musa de seu marido, um pintor de alto renome que havia isolado a ela e a si no torreão do castelo até o dia em que completou o trabalho.

A narrativa compreende um evento que se desenrola em apenas uma noite, em um espaço definido. ${ }^{2}$ Desde o início da narração cria-se um grande mistério em torno da figura do narrador. Muito pouca coisa sabemos a respeito dele; o seu nome nos é desconhecido, assim como a razão pela qual ele foi ferido. A ação se concentra em uma pequena sala na qual o narrador e seu criado resolvem passar a noite, localizada em uma parte afastada do resto do castelo:

Aboletamo-nos em uma das salas menores e menos suntuosamente mobiliadas, localizada num afastado torreão do edifício. Eram ricas, embora estragadas e antigas, suas decorações. Tapeçarias pendiam das paredes, adornadas com vários e multiformes troféus de armas, de mistura com um número insólito de quadros de estilo bem moderno em molduras de ricos arabescos de ouro. Por esses quadros, que enchiam não só todas as paredes, mas ainda os numerosos ângulos que a esquisita arquitetura do castelo formava, meu delírio incipiente me fizera talvez

\footnotetext{
${ }^{2}$ A técnica utilizada aqui é chamada de unfolding, que consiste em um afunilamento do espaço como forma de jogar com a narrativa. Percebemos que o narrador e seu criado chegam ao castelo, entram em uma sala localizada em um torreão afastado do prédio principal, o narrador se deita na cama e logo depois encontra o retrato. Tal técnica é também usada no conto "A máscara da morte rubra", de 1842, que trata de uma misteriosa peste que se alastra pelo reinado do Príncipe Próspero. No auge da epidemia, ele resolve fazer um baile em seu castelo, e é na descrição dos salões que o unfolding aparece: primeiro na descrição de uma janela, e depois na descrição de um relógio de ébano, que mais tarde desempenhará um papel importante na narrativa.
} 
tomar profundo interesse. Assim é que mandei Pedro fechar os pesados postigos da sala pois já era noite, acender as velas de um enorme candelabro que se achava à cabeceira de minha cama e abrir completamente as franjadas cortinas de veludo preto que envolviam o leito. Desejei que tudo isso fosse feito, a fim de que pudesse abandonar-me senão ao sono, pelo menos, alternativamente, à contemplação desses quadros e à leitura de um livrinho que encontrara sobre o travesseiro e que continha a crítica e a descrição das pinturas. (POE, 2001, p. 280).

A descrição nos leva a crer que o castelo foi provavelmente habitado por membros da alta aristocracia europeia devido às decorações que, apesar de gastas e antigas, revelam a opulência de uma classe favorecida. Além disso, temos as tapeçarias, os troféus e os quadros decorados com arabescos de ouro, elementos que, além de remeter a uma suposta riqueza, conferem uma aura de exotismo ao local. As cortinas de veludo negro que envolvem o leito dão um ar fúnebre ao quarto, e as velas do candelabro são as únicas a iluminar o cômodo, criando uma penumbra que o torna apropriado para a ambientação de uma narrativa de mistério. É interessante perceber que toda esta descrição se baseia nas impressões subjetivas do narrador, que fica fascinado pela suntuosidade do castelo. Esta é uma das prerrogativas da narração em primeira pessoa, na qual a visão da realidade é muito parcial, já que temos a voz de uma única pessoa. O teórico Wayne Booth afirma que a escolha pelo foco narrativo em primeira pessoa acaba sendo limitadora, pois "[...] este narrador tem acesso restrito à informação, levando o autor implícito a se perder em improbabilidades",3 (BOOTH, 1983, p. 150). Este narrador não é necessariamente um mentiroso, mas muito pouco confiável, porque não é onisciente e só pode falar por si mesmo, nunca pelos outros personagens.

Após passar muito tempo lendo e contemplando os quadros, à meia-noite ele resolve mudar a posição do candelabro de forma a iluminar em cheio o livro que estava lendo. No entanto, o gesto provoca um efeito inesperado, iluminando uma parte da sala que até o momento estava escondida por uma das colunas da cama e desvendando o "retrato de uma jovem no alvorecer da feminilidade” (POE, 2001, p. 280). Neste ponto da narrativa percebemos que a luz adquire um significado simbólico, pois ilumina o que até então estava na escuridão, tanto na sala quanto na mente de quem narra. Este insight causado

3 “" [...] this type of narrator has a more restrict acess to information, making the implicit author get lost in improbabilities". (minha tradução) 
pela iluminação do retrato oval provoca uma significativa alteração no estado de espírito do narrador, que passa de sonolento a completamente desperto. A modificação se estende também ao leitor, que fica curioso para saber detalhes a respeito do quadro. Esta mudança causa ainda uma mudança nos próprios rumos da narrativa, que passa a ter o retrato como elemento central. A qualidade da moldura chama a atenção do narrador, bem como a figura da jovem, que irradia vivacidade:

O retrato, como já disse, era o de uma jovem. Apenas a cabeça e os ombros, feitos na maneira tecnicamente chamada vignette, e bastante no estilo das cabeças favoritas de Sully. Os braços, o colo, e mesmo as pontas do cabelo luminoso perdiam-se imperceptivelmente na vaga porém profunda sombra formada pelo fundo do conjunto. A moldura era oval, ricamente dourada e filigranada à mourisca. Como obra de arte, nada podia ser mais admirável do que a própria pintura. Mas aquela comoção tão súbita e tão intensa não me viera nem da execução da obra nem da imortal beleza do semblante. Menos do que tudo poderia ter sido minha imaginação que despertada de seu semitorpor, teria tomado aquela cabeça pela de uma pessoa viva. Vi imediatamente que as peculiaridades do desenho, do trabalho do vinhetista e da moldura deviam ter de pronto dissipado tal ideia, impedido mesmo seu momentâneo aparecimento. Permaneci quase talvez uma hora semi-erguido, semi-inclinado, a pensar intensamente sobre tais pormenores, com a vista fixada no retrato. Por fim, satisfeito com o verdadeiro segredo de seu efeito, deixei-me cair na cama. Descobrira que o encanto do retrato estava na expressão de uma absoluta aparência de vida que a princípio me espantou para afinal confundir-me, dominar-me e aterrar-me. (POE, 2001, p. 281)

A incrível aparência de vida que a figura da jovem apresenta faz o narrador pensar que se trata de uma pessoa viva, dado o estado de sonolência no qual se encontra. Todavia, as características da pintura, as particularidades do desenho e a rica decoração da moldura o fazem de pronto perceber que se trata de uma obra de arte. No retrato, aparecem apenas a cabeça e os ombros, feitos à maneira vignette, um efeito visual que faz com que a imagem da moça apareça mais do que os seus braços, colo e cabelos. Tais detalhes se perdem nas sombras do fundo do quadro, o que mais uma vez confere uma aura de mistério à obra. A descrição da moldura, que é filigranada à mourisca, ou seja, ornamentada com delicados desenhos geométricos, aponta para a enorme sofisticação de quem a produziu, além de evidenciar mais uma vez o profun- 
do conhecimento do narrador, que parece entender muito bem de pintura, já que cita o nome de Thomas Sully (1783-1872), um famoso retratista norte-americano de origem inglesa. Seu fascínio em relação à fisionomia da jovem faz com que ele permaneça quase uma hora com os olhos presos no quadro realizando a sua fruição estética. Experimenta uma confusão de sensações: espanto, terror, medo, dominação. Cabe ressaltar que o narrador está quase adormecendo quando vê o retrato oval, o que nos leva a pensar que ele possa estar sonhando, ou até mesmo delirando. Não temos, portanto, certeza do que ele narra, o que nos mostra que ele é um narrador pouco confiável, pois, além de narrar unicamente de seu ponto de vista, está no limiar entre o sono e a vigília, entre o sonho e a realidade.

Ele muda novamente a posição do candelabro, a fim de afastar a causa de sua aguda agitação, para poder ler o trecho que conta a história do quadro. A partir daí iremos conhecer a história do pintor e de sua jovem amada através da técnica da história dentro da história (story within a story). Esta técnica é muito usada em obras ficcionais e apresenta uma série de finalidades. A primeira delas é a de simplesmente desviar a atenção do leitor do enredo principal, oferecendo-lhe uma oportunidade de divagar e refletir sobre outros aspectos deste enredo. Uma story within another story pode também ser usada para oferecer aos personagens exemplos sobre como devem agir, funcionando como possíveis lições de moral ou como uma forma de satirizar o conteúdo da narrativa principal. Geralmente as duas narrativas apresentam fortes paralelos entre si, o que muitas vezes faz com que a segunda possa ser usada para revelar uma verdade que ainda não veio à tona na primeira. Acreditamos que este possa ser o caso que estamos analisando em "O retrato oval", uma vez que o trecho contido no volume esclarece a "verdade" em relação ao quadro. É interessante ressaltar que não sabemos se a história relatada é mesmo verdadeira, não só pelo fato de o narrador/leitor não ser confiável, mas também pelo fato de este manuscrito ter sido encontrado em um livro antigo, que poderia muito bem ser um livro de ficção. Há um grande mistério rondando este volume, bem como o narrador da nova história, que é também desconhecido. Apesar de relatar os fatos na terceira pessoa, ele parece nutrir uma grande solidariedade em relação à jovem, que de acordo com ele perdeu a vida ao se tornar uma obra de arte:

Era uma donzela da mais rara beleza e não só amável como cheia de alegria. E maldita foi a hora em que ela viu, amou e desposou o pintor. Ele era apaixonado, estudioso, austero e já tinha na Arte a sua desposada. Ela, uma donzela da mais rara beleza e não só amável como cheia de 
alegria, toda luz e sorrisos, travessa como uma jovem corça; amando com carinho todas as coisas; odiando somente a Arte, que era sua rival; temendo apenas a paleta, os pincéis e os outros sinistros instrumentos que a privavam da contemplação do seu amado. Era pois terrível coisa para essa mulher ouvir o pintor exprimir o desejo de pintar o próprio retrato de sua jovem esposa. Ela era, porém, humilde e obediente, e sentava-se submissa durante horas no escuro e alto quarto do torreão, onde a luz vinha apenas de cima projetar-se, escassa, sobre a alva tela. Mas ele, o pintor, se regozijava com sua obra, que continuava de hora em hora, de dia em dia. E era um homem apaixonado, rude e extravagante, que vivia perdido em devaneios; assim não percebia que a luz que caía tão lívida naquele torreão solitário ia murchando a saúde e a vivacidade de sua esposa, visivelmente definhando para todos, menos para ele. Contudo, ela continuava ainda e sempre a sorrir, sem se queixar, porque via que o pintor (que tinha alto renome) trabalhava com fervoroso e ardente prazer e porfiava, dia e noite, por pintar quem tanto o amava, mas que todavia, se tornava cada vez mais triste e fraca. E na verdade alguns que viram o retrato falavam em voz baixa de sua semelhança como de uma extraordinária maravilha, prova não só da mestria como de seu intenso amor por aquela a quem pintava de modo tão exímio. Mas afinal, ao chegar o trabalho quase a seu termo, ninguém mais foi admitido no torreão, porque o pintor se tornara rude no ardor de seu trabalho e raramente desviava os olhos da tela, mesmo para contemplar o semblante de sua esposa. E não percebia que as tintas que espalhava sobre a tela eram tiradas das faces daquela que se sentava a seu lado. E quando já se haviam passado várias semanas e muito pouco a fazer, exceto uma pincelada sobre a boca e um colorido nos olhos, a alegria da mulher de novo bruxuleou, como a chama dentro de uma lâmpada. E então foi dada a pincelada e completado o colorido. E durante um instante o pintor ficou extasiado diante da obra que tinha realizado mas em seguida, enquanto ainda contemplava, pôs-se a tremer e, pálido, horrorizado, exclamou em voz alta: "Isto é na verdade a própria vida." Voltou-se, subitamente, para ver a sua bem-amada. . . Estava morta! (POE, 2001, p. 281).

A partir da leitura deste trecho, podemos interpretar a feminilidade como algo construído pelo olhar masculino, sendo o lugar de uma beleza que se fixa para ser admirada. A jovem é idealizada desde o momento em que o narrador descobre a pintura, sendo descrita como uma moça muito bela, jovem, alegre, amável, "travessa como uma corça", que amava todas as coisas menos a arte, que era sua rival. Seu marido é o seu extremo oposto: um 
homem extravagante, rude e apaixonado pela arte. Ao associar sua esposa com a arte, o pintor se realiza espiritualmente, mas nela observamos exatamente o contrário: perde sua vitalidade, definha e morre. Ao escolher a personagem feminina como objeto de representação, o artista tenta, ao mesmo tempo, eliminá-la em sua materialidade ameaçadora e imortalizá-la em sua beleza e juventude. O resultado deste esforço é o retrato oval, espaço no qual a jovem se transforma em um simulacro, isto é, uma imitação de mulher, e em um verdadeiro espetáculo para o olhar masculino.

Desta maneira, é possível observar uma assimetria de poder entre o pintor e sua esposa, e tal assimetria parece ser o eixo sobre o qual toda a narrativa se constrói, sendo a partir dela que se origina o retrato oval. De um lado, temos o pintor, o artista demiurgo por excelência, que tem o poder da criação; de outro, a personagem feminina, que se encontra em desvantagem, pois morre para dar lugar a uma obra de arte. Para Elisabeth Bronfen, o retrato representa "o assassinato metafórico do feminino, fazendo da mulher um ícone, uma santa, evocando sua morte antes que ela ocorra" (BRONFEN, 1992, p.119). A eliminação material da jovem é desvantajosa porque a silencia enquanto sujeito pensante e atuante e a transforma em um objeto de sedução passiva, criada pelo artista, que representa a figura feminina da forma que mais lhe convém. Portanto, o impasse entre a morte física da jovem e sua sobrevivência no quadro se resolve através da estetização de sua figura, processo este que fabrica um ser de ilusão, que pode até exercer fascínio sobre o homem, mas nunca deixará de ser um objeto de contemplação, um fetiche do pintor, uma espécie de fantasma do personagem masculino.

\section{Considerações finais}

A partir da análise do conto "O retrato oval”, é possível afirmar que o artista, ao pintar o quadro de sua amada, constrói uma imagem não da mulher "real", mas sim uma imagem na qual possa se refletir e buscar sua própria identidade. A personagem feminina nunca é afirmada e valorizada como sujeito autônomo, e sim como o espelho do personagem masculino, espelho este materializado em uma obra de arte que se presta à contemplação e admiração também masculinas. Neste sentido, a representação da identidade feminina nesta narrativa pode nos dizer muita coisa a respeito das relações de poder em uma sociedade patriarcal na qual muitas mulheres, assim como a jovem 
do retrato, eram musas interrompidas e tinham suas vozes silenciadas. Tais interpretações são possíveis graças à adoção de uma perspectiva de gênero, que pode não dar conta de todos os aspectos de uma obra, mas revela de que maneira se constroem as configurações de gênero dentro não só do texto ficcional, mas também de uma determinada sociedade.

\section{Referências}

BELLIN, G. P. Musas interrompidas, vozes silenciadas: a representação da figura feminina em três contos de Edgar Allan Poe. 130f. Dissertação de mestrado. Curitiba: UFPR, 2010.

BOOTH, W. The rethoric of fiction. Chicago: University of Chicago Press, 1983.

BRONFEN, E. Over her dead body: death, femininity and the aesthetic. Oxford: Oxford University Press, 1992.

FELSKI, R. Literature after feminism. Chicago: University of Chicago Press, 2003.

. The gender of modernity. Cambridge, Mass: Cambridge University Press, 1995.

LAURETIS, T. D. A tecnologia do gênero. In: HOLLANDA, Heloísa Buarque de. (Org.) Tendências e impasses: o feminismo como crítica da cultura. Rio de Janeiro: Rocco, 1994. p.206-237.

LIMA, L. C. Dispersa demanda. Rio de Janeiro: Francisco Alves Editora, 1981.

POE, E. A. Ficção completa, poesia e ensaios. Trad. Oscar Mendes. Rio de Janeiro: Aguilar, 2001.

SCOTT, J. Gênero: uma categoria útil de análise histórica. Educação e Realidade. Porto Alegre: v.16, n.2, p.5-22, 1990.

SMITH, C. B. Representações da Ofélia de Shakespeare na Inglaterra vitoriana: um estudo interdisciplinar. 225f. Tese de doutorado. Curitiba: UFPR, 2007.

Recebido para publicação em 08 nov. 2010. Aceito para publicação em 01 mar. 2011. 